\title{
BITCOIN AS A NEW CURRENCY
}

\section{Prof. Janusz Brzeszczyński}

University of Łódź

Department of Capital Market and Investments

Newcastle Business School (NBS), Northumbria University, Newcastle-upon-Tyne

e-mail: janusz.brzeszczynski@northumbria.ac.uk

ORCID: 0000-0003-0975-8814

Prof. Jerzy Gajdka ${ }^{1}$

Tomasz Schabek, Ph.D. ${ }^{2}$

University of Łódź

Department of Capital Market and Investments

${ }^{1}$ e-mail: jerzy.gajdka@uni.lodz.pl

ORCID: 0000-0003-1870-3129

${ }^{2}$ e-mail: tomasz.schabek@uni.lodz.pl

ORCID: 0000-0002-4362-8864

Received 6 December 2019, Accepted 29 October 2020

\begin{abstract}
Research background: Bitcoin is the most popular financial instrument within the new cryptocurrencies class, which emerged in the wake of the financial crisis of 2007/2008.

Purpose: The purpose of this paper is to provide an analysis of Bitcoin from the perspective of the Polish market investor. More specifically, the aim of the empirical research presented in this study has been twofold: (1) comparison of Bitcoin with other currencies using returns and risk captured by the standard deviation of returns and (2) assessment of the sensitivity of the BTC/PLN exchange rate to the NBP's monetary policy announcements.

Results: Bitcoin appears to be weakly related to other currency exchange rates against the Polish zloty and the monetary policy announcements of the National Bank of Poland (NBP) have, effectively, no influence on the determination of the BTC/PLN exchange rate.

Novelty: We discuss extensively the Bitcoin as a new asset on the financial market and we present the investigation of the BTC/PLN reactions to the monetary policy announcements in Poland, which is a novel analysis for this instrument using the Polish market data.
\end{abstract}

Keywords: Bitcoin, Cryptocurrency, Foreign Exchange Rates, National Bank of Poland (NBP)

JEL calassification: C58, E52, E58, G15 


\section{Introduction}

Cryptocurrencies, known also as internet currencies, are one of the most important innovations, which were launched in financial markets at the turn of the 20th and the $21 \mathrm{st}$ centuries. They gained particular significance in the wake of the financial crisis of 2007/2008. While there are hundreds of cryptocurrencies (in 2018 their number was estimated to exceed 1,600 (Fesseden, 2018), only a few of them have become popular and economically meaningful.

This paper analyses Bitcoin (BTC), which is the most widely used cryptocurrency. Bitcoin creators and its advocates view it as a decentralized, diversified and a borderless currency, which can function without any central issuing institution and outside of the banking systems, beyond the governments' control and the use of which is determined by access to the internet. As Bitcoin circulates without the intermediation of any financial institutions, such as banks etc., no commission fees are involved. As any other currency, BTC can be used as a means of exchange and as an investment asset. However, besides the many advantages of Bitcoin, it also suffers from certain weaknesses which create uncertainty for its users.

In this study, we analyse various investment aspects of Bitcoin from the perspective of the Polish market investor. The importance of this cryptocurrency in Poland has been increasing rapidly, although the availability of relevant statistical data characterising the Bitcoin market is still very limited.

According to Kacwin and Piech (2017), between October 2016 and October 2017 the annual turnover on all cryptocurrency exchanges in Poland increased by $1,450 \%$ and reached the level of 5.50 bn PLN. They estimated that the average annual growth during 3 years since 2015 was $290 \%$, however assuming the exponential trend of changes they predict that in 2020 the total turnover will reach 187 bn PLN and 640 bn PLN in 2021. Bitcoin mining also plays an important role in Poland in the Bitcoin industry (because it requires a lot of energy, Kacwin and Piech (2017) calculated that in 2021 the miners will pay $100 \mathrm{mln}$ PLN as the VAT tax, which is included in electricity prices), which further motivates the analyses regarding this new assset. However, despite the existence of the statistical data indicating the importance of Bitcoin, in Poland the research in this area has been so far very limited.

Therefore, the main objective of this paper is to contribute twofold to the existing literature. First, we discuss the characteristics of Bitcoin (in particular as money and as an investment). Second, we investigate two issues related to investing in Bitcoin from the Polish perspective, i.e. we assess the investment profitability in comparison with other traditional currencies and we investigate the sensitivity of the BTC/PLN exchange rate to the Polish central bank's monetary 
policy announcements, which have been evidenced in previous studies to have a consistent impact on the PLN exchange rates (see Brzeszczyński and Kutan (2015) and Brzeszczyński, Gajdka and Kutan (2017 and 2019), among others). In summary, in this paper we provide a comparison of Bitcoin with other currencies from the perspective of the Polish market.

\section{The origins of Bitcoin}

Throughout most of the 19th and the 20th centuries, major world currencies were based on gold or on other precious metals. For thousands of years, their value had been determined by the metal of which they were made, i.e. typically gold and silver. The gold standard was abandoned by most world economies in the years 1920-1971. These decisions were initially determined mainly by the shortage of funding after the two world wars and the global output of gold lagging behind the rate of economic growth (Yermack, 2015). At present, practically all economies use fiduciary money, i.e. the money which value is not based on tangible assets (e.g. bullion) but on a formally established monopoly of its use as the legal tender on a given territory and which value derives from the trust in its issuer. Different kinds of fiduciary money have also been used for thousands of years but sooner or later some of them became almost worthless, when governments' needs clashed with public funding shortages, as it happened during and in the aftermath of World War I (Yermack, 2015). The trust in fiduciary money was also undermined by the financial crisis of 2007-2008 and the governments' actions, which followed afterwards, aimed at mitigating its impacts. The cause of the crisis was attributed, inter alia, to the design of the financial system and governments' and financial institutions' control of money supply. Cryptocurrencies, such as Bitcoin, which are free from the weaknesses of fiduciary money and metal-based money, emerged as a response to this situation. The coincidence between the birth of Bitcoin and the financial crisis in the first decade of the 21 st century is by no means accidental (Saleem, 2018).

\section{The mechanism of Bitcoin's functioning}

Bitcoin's functioning was described for the first time in 2008 by Satoshi Nakamoto, whose true identity is not known, in the publication titled: "Bitcoin: A Peer-to-peer Electronic Cash System" (Nakamoto, 2008). According to its characterization, Bitcoin is not based on its users' trust in the central issuing authority, as in the case of fiduciary currencies, but it uses a distributed 
database and cryptography to ensure the basic security of transactions, i.e. to guarantee that their current holders spend them only once.

The Bitcoin system is not controlled by any central administration. It is designed to prevent all entities, including financial institutions and government agencies, from running a monetary policy that could arbitrarily increase the number of Bitcoin units in circulation. At the same time, the system allows Bitcoin holders to remain anonymous and make transfers without revealing their identity.

The production (called: "mining") of new Bitcoin units by a network of users involves a special condition, which is statistically unlikely to be met. The probability of success depends on the ratio between the computational power that a user can contribute to the network and the computational power of the entire network. At present, the computational power requirement is substantial, and a variety of methods are used to assess the user's contribution (Rosenfeld, 2011). The number of Bitcoin units mined per lot constantly changes. Currently, 12.5 BTC are paid for each block mined, which hardly compares with 50 BTC paid after the system was launched or even 25 BTC that could be obtained about four years ago (the reduction from 25 BTC to 12.5 BTC took place in July 2016). The number of new Bitcoins is reduced by half every four years. At present it is 6.25 BTC and according to the estimates presented by BitcoinBlockHalf.com, it will fall again (to 3.125) in 2024 ("Bitcoin Block Reward Halving Countdown" (2020). The pattern of reductions has been programmed in advance, so that the number of Bitcoins in circulation will never exceed 21,000,000, with the final limit expected to be achieved by the year 2040. Figure 1 shows how the number of BTC has been changing in the past and how it will be evolving in the future.

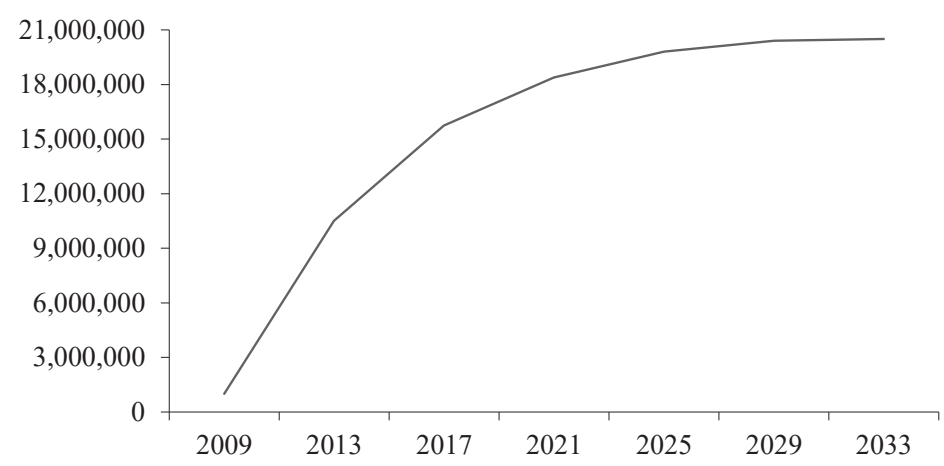

Figure 1. Total number of Bitcoins in circulation over time from 2009 to 2033 Source: based on Nian and Chuen (2015b). 
According to the advocates of Bitcoin who support this mechanism, the purpose of a limited and decelerating supply is to ensure that with the growing popularity of Bitcoin there will be increasingly more units of existing goods and services per each Bitcoin. Therefore, unlike the US dollar or the Polish złoty, Bitcoin is intended to appreciate rather than depreciate over time. Those who allow access to the computational power of their computers will be rewarded even after the last Bitcoin has been mined through commissions on transactions (as it is already happening (Rosenfeld, 2011).

Bitcoin transfers between the users' accounts are encrypted, so all transactions are public and stored in a distributed database. Without going into too many technical details, a Bitcoinbased transaction is carried out as follows (for more details see e.g. Vujičić et al., 2018). A network participant has a wallet which stores a number of cryptographic key pairs. Bitcoin units contain a public key in form of the address of their current owner. When user $A$ transfers some number of Bitcoins to user $B$, the latter's public key (address) is attached to the transfer and the transaction is authorized using the private key. A transaction delivered to other nodes does not become "official" until it is added to the system and confirmed on the list of all known transactions. The confirmation is based on the mathematical proof of the performed operations to make sure that Bitcoins are not spent twice and to prevent fraud. All attempts of using Bitcoins that have already been spent are thwarted by the network.

\section{Bitcoin and the functions of money}

According to its advocates, the Bitcoin should perform the functions of money. While there exist many views on what these roles include, it is usually assumed that the most important of them are: a unit of account, a medium of exchange and a store of value. These three functions mean, respectively, that money allows the prices of goods and services to be expressed and compared in monetary units, that it enables to transfer payments and transactions where the delivery of goods and the payment take place at the same time and that it can be used to make payments at the present time and in the future.

Bitcoin falls short of performing those three functions for many reasons. Firstly, it is still insignificant as a medium of exchange. Although the number of businesses that accept Bitcoins is rising, there are still relatively very few of them. Moreover, most of these entities are in the IT industry: some selling Bitcoin devices and others being Bitcoin exchanges servicing Bitcoin investors. However according to Athey, Parashkevov, Sarukkai and Jing Xia (2016) the key 
use cases of that cryptocurrency are: the use of Bitcoin to buy illegal substances (as drugs or firearms) and international payments.

Yermack (2015) estimated the number of Bitcoin transactions worldwide in 2014 at around 70,000 per day. However, most of them were carried out between investors and only 15,000 involved the actual sale of goods and services. As the world population exceeds 7 billion people, and each person is making several transactions per one day, this number is extremely low (in fact, it represents only about $0.00002 \%$ of all transactions worldwide). Yermack (2015) argues that it is smaller than the number of businesses that might be interested in exchanging goods and products using Bitcoins.

The main hurdles in using Bitcoin as a medium of exchange seem to be the relatively small number of Bitcoins in circulation and problems with new Bitcoin issues. If a consumer is not a Bitcoin miner (and to be one a substantial investment in computer hardware is necessary), they have to purchase Bitcoins at some exchange or from a dealer and then find a way to store them safely. It needs to be noted here that Bitcoin exchanges are characterized by relatively low liquidity and high spreads between the buying and selling prices. Moreover, it is not possible to buy Bitcoins by paying with a credit card (which is a common practice in the contemporary world); because there are no Bitcoin credit cards (although there exist some Bitcoin debit cards). Finally, Bitcoin payments are subject to a verification procedure that takes about 10 minutes on average. Theoretically, the seller has the option of accepting a transaction in a shorter time, but it increases the risk of an attempt to try to spend the same Bitcoins on another product.

For money to perform the function of a unit of account, it must enable the consumer to assess and compare the value of a product against its alternatives. (Yermack 2015). For instance, if one product is priced at 4 PLN and another one at 2 PLN, it is obvious that the first one is priced twice as high. However, while using Bitcoin as a unit of account, many problems emerge. Firstly, its exchange rates are characterized by high volatility (see e.g. Lo and Wang, 2014). Because Bitcoin's value against other currencies changes considerably every day and even every hour, vendors accepting Bitcoin payments must be ready to adjust their prices very quickly. This requirement causes problems to both buyers and sellers. In an economy using Bitcoin as the primary currency, it would be a mild inconvenience, but for the time being no such economic system exists. The core of the problem is that different exchanges have simultaneous prices for Bitcoin, which is an outright violation of the law of one price. Consequently, some sellers set their prices using an average value of Bitcoin's prices quoted by different exchanges during the recent 24 hours period, but such an average price is obviously not the price for which Bitcoin can be sold or bought at the given moment. Another problem haunting Bitcoin as a unit of account is 
the high cost of buying it in relation to the price of the target service or a good, which leads to the situation that Bitcoin-denominated prices have four or five decimal places. For consumers, such prices will be inevitably confusing, especially that in no other currency the prices are quoted in an equally strange manner.

The store of value function of money means that it can be used to acquire goods and services at present time as well as in the future. According to Athey et al (2016) the microdata support the conclusion that this is the most important case for use of Bitcoin. For this function to be fulfilled, the economic value of money that has been stored away should not depreciate over time. Historically, it emerged as people carefully hid their money from thieves or deposited it in banks for the same purpose. The traditional strategies employed to protect money from being stolen (such as hiding it in secret places) do not apply to Bitcoin, which is an intangible currency and can only be kept in a computer account called a "digital (e-) wallet". Protecting the account from computer crime continues to be the toughest challenge faced by Bitcoin users (see e.g. Yermack, 2015). One protective option is to use the services of firms keeping Bitcoin deposits, some of which have insurance contracts with specialized insurers as an additional safeguard. However, even if such a strategy is effective, it always involves an extra cost for the Bitcoin owner who is charged by the service provider and the insurer. Some providers offer to keep clients Bitcoins in sites that have never been accessed from any computer (virgin sites). The downside of this type of protection from hackers is that it takes time for Bitcoin owners to access their accounts and it also incurs more costs. Assuming that the problem of protecting assets from unauthorized access is solved, a Bitcoin owner is then faced with yet another problem: the volatility of the exchange rate between Bitcoin and respective other currencies. In our study, the standard deviation of monthly returns of the BTC/PLN exchange rate is estimated at a $66 \%$ level, which clearly shows the level of risk of keeping Bitcoin even in short time periods.

Another important characteristic of Bitcoin is its weak link to other currencies (see e.g. Yermack (2015)). Macroeconomic events that usually affect foreign exchange markets appear to be irrelevant for the price of Bitcoin. For Bitcoin to be able to function as a store of value and a unit of account, the daily fluctuations in its price should also be much smaller than what they are today. The behavior of the Bitcoin exchange rate is more similar to the behavior of a risky speculative investment rather than to other traditional currencies. Other obvious problems in using Bitcoin as money include the already mentioned issue of the decimal places in Bitcoindenominated prices, the time-consuming and complex verification of transactions and the need for its users to have relatively sophisticated computer knowledge. 
Finally, its weak correlation with other currencies causes problems with finding alternative investment assets to offset the risk of Bitcoin investments. Another issue specific to Bitcoin is that the customers who found goods or services, for which they paid with Bitcoins, to be of inferior quality, have no legal tools to force the sellers to replace or refund them, because such transactions are not regulated by governments'. In fact, Bitcoin is not controlled by the authority of any country.

\section{Bitcoin as an investment}

While the number of Bitcoin-based transactions has been growing, most of them are related to various financial investments conducted by speculators. The most popular ones consist of buying Bitcoins at an exchange and selling them later to make a profit.

Another convenient method for investing in Bitcoin are Contracts for Difference (CFD) where an investor bets on whether the exchange rate of some asset (e.g. Bitcoin in this case) will increase or decrease in the future (see: “Jak inwestowac w Bitcoin”, 2020). If the CFD buyer's prediction is correct, the difference between exchange rates quoted at the beginning and at the termination of a CFD is paid out by the broker. What distinguishes CFDs from other instruments is the availability of a 'leverage' that allows the investors to make a much larger investment than in the case of traditional stock market transactions. For instance, with a leverage ratio of 1 to 10 , they can buy ten times more Bitcoins than without it. However, investors using leverage should obviously expect also much higher fluctuations in profits and losses, i.e. much higher risk.

Another instrument available to Bitcoin investors are binary options, which are similar to CFDs in that they also involve bets on whether the value of an asset will rise or fall. In the case of a binary option, the investors indicate the amount they want to invest and predict whether the Bitcoin exchange rate will rise or fall before the expiry date of the contract. A binary option contract can run from a minimum of 60 seconds to a maximum of several weeks. The risk of investing in this instrument is also very substantial.

The rising popularity of such investments prompted the National Bank of Poland and the Polish Financial Supervision Authority to announce that "virtual currencies" were neither issued nor guaranteed by the NBP, they are not money (i.e. a legal means of exchange or currency), they could not be used by taxpayers to pay their liabilities and they did not meet the criterion of wide acceptance at points of sale. The public were also reminded that "virtual currencies" are not e-money and that both the payment services act of 19 August 2011 and the financial instruments trading act of 29 July 2005 do not apply to them. This warning was supported by 
five main arguments explaining in more detail the risks related to the use of Bitcoin. However, the NBP document also indicated that trading in virtual currencies does not breach national or EU laws. This means that despite the regulators' concerns about cryptocurrencies, including Bitcoin, as a form of money and as an investment asset, their use in Poland is entirely legal.

\section{Earlier studies on Bitcoin}

While the number of the existing studies is rising, the Bitcoin literature is still at the early stage of development. Current research is mainly focused on the issues that have not yet been solved, such as the legal aspects of Bitcoin's functioning (Sapovadia, 2015; Plassaras, 2013; Nian, Chuen, 2015; Levin, O’Brien, Zuberi, 2015; Lim, 2015, Marian, 2015), taxation problems (Bal, 2015; Roberts, 2017; Marian, 2013) or the financing of illegal activities (Saito, 2015; Choo, 2015; Kossov, Dykes, 2018).

Another line of literature investigates the financial aspects of investing in Bitcoin and it concentrates on such problems as, for example, Bitcoin returns (Mukherji, 2020), Bitcoin and the risk-free rate (Wesner, 2015), Bitcoin and currency investment portfolios (Carrick, 2016), efficiency of the Bitcoin market (Bartos, 2015), forecasting Bitcoin exchange rates (Huang, Huang, Ni, 2019; Ji, Kim, Im, 2020) or determinants of the Bitcoin exchange rates (Wang, 2014; Athey et al., 2016). In particular, Athey et al. (2016) attempted to demonstrate that Bitcoin exchange rates can be fully determined by two market fundamentals: the steady state transaction volume of Bitcoin when it is used for payments and the evolution of beliefs about the likelihood that the technology survives. However, empirical evidence relying on Bitcoin prices and its utilization provides mixed results about the ability of the model to explain the Bitcoin exchange rate.

Overall, the research mentioned above is focused mostly on global, or the US investor's, viewpoint and it does not refer specifically to Polish conditions. Hence, in our study we analyse the investments in Bitcoin from the Polish investor's perspective.

\section{Empirical analysis}

\subsection{Research objective}

The aim of our research is twofold: (1) we compare Bitcoin with other currencies using two basic measures, i.e. rate of return and risk captured by the standard deviation of returns and (2) we assess the sensitivity of the BTC/PLN exchange rate to the NBP's monetary policy announcements. 
The main hypotheses, which have been tested below, are as follows:

1. There exists a strong correlation between the returns of the Polish złoty-denominated investments in the main global currencies and the Bitcoin returns.

2. The response of the BTC/PLN exchange rate to the NBP's monetary policy announcements is statistically significant.

\subsection{Data}

We collected data about daily Bitcoin exchange rates and macroeconomic announcements for the period from July 2010 to September 2020. The sources of the data are Bloomberg and the Stooq database (www.stooq.pl).

Our study covers data about USD/PLN, EUR/PLN, GBP/PLN, JPY/PLN and BTC/PLN exchange rates, which were obtained from the Stooq and Bloomberg databases.

The NBP's monetary policy announcements regarding the interest rate changes (Interest rates), the M3 money supply (M3), NBP's reserves (Reserves), current account turnover (Current Account) and the minutes of the Monetary Policy Council sessions (Minutes) were collected from the NBP. The types and numbers of announcements used in the study are shown in Table 3.

\subsection{Research methodology}

Our research was divided into two stages. In the first stage, the returns and the risk of Bitcoin investments, measured by standard deviation, were analyzed. The profitability, risk and correlations between the exchange rates of the selected other currencies and Bitcoin were also compared. In the second stage, the BTC/PLN exchange rate's response to the NBP's monetary policy announcements was assessed.

The reactions of the daily Bitcoin exchange rate returns to the NBP's announcements were investigated based on the following mean equation of the GARCH $(1,1)$ model:

$$
\begin{gathered}
r_{t}^{\text {PLNBTC }}=\beta_{0}+\sum_{j=1}^{J} \sum_{k=-K}^{K} \beta_{j, k} \cdot D U M_{t-k}^{j}+\sum_{m=1}^{M} \beta_{m} \cdot r_{t-m}^{\text {PLNBTC }}+ \\
+\sum_{n 1=-N 1}^{N 1} \beta_{n 1} \cdot r_{t-n 1}^{P L N U S D}+\sum_{n 2=-N 2}^{N 2} \beta_{n 2} \cdot r_{t-n 2}^{P L N E U R}+\varepsilon_{t}^{i}
\end{gathered}
$$

where: $r_{t}^{B T C / P L N}$ is the daily return of the BTC/PLN exchange rate; $D U M_{t-k}^{j}$ is a dummy variable taking on the value of 1 when a given $j$-th macroeconomic announcement was released or 0 otherwise; $J$ stands for five macroeconomic announcements (current account balance, money supply M3, reserves of NBP, minutes and interest rate); $K$ is the lag/lead of each $j$-th 
macroeconomic announcements (from -2 to +2 days); $M$ is the lag of rates of return of the PLN/ BTC exchange rate; $N 1$ and N2 are lags/leads for the control variables, i.e. the rates of return of the USD/PLN and EUR/PLN exchange rates, respectively (from -2 to +2 days), $\beta_{0}, \beta_{j, k}, \beta_{m}$, $\beta_{n 2}, \beta_{n 1}$ are the estimated coefficients. $J$ is equal to the number of the types of announcements $(J=5)$. The maximum number of leads and lags is \pm 2 days, because the focus of our analysis is on the short-term effects.

All estimations were also subject to autocorrelation and heteroscedasticity tests. When autocorrelation was present, the relevant $\mathrm{AR}$ and/or MA terms were added in order to remove it. In case of heteroscedasticity, GARCH $(1,1)$ was a sufficient specification, which ensured that heteroscedasticity was entirely eliminated.

\subsection{Results}

Table 1 presents the monthly statistics regarding the rates of return and the standard deviation as a measure of risk for investments in five currencies against the PLN: USD, EUR, GBP, CHF and JPY as well as Bitcoin.

Table 1. Monthly rates of return and risk of investments in currency exchange rates in the period from July 2010 to September 2020

\begin{tabular}{|l|c|c|c|c|c|}
\cline { 2 - 6 } \multicolumn{1}{c|}{} & Mean & Median & Std. Dev. & Max. & Min. \\
\hline USD/PLN & 0.002516 & 0.001067 & 0.035743 & 0.146827 & -0.07381 \\
\hline EUR/PLN & 0.001171 & -0.000680 & 0.017801 & 0.069627 & -0.05223 \\
\hline GBP/PLN & 0.000706 & -0.000560 & 0.028816 & 0.101999 & -0.08331 \\
\hline CHF/PLN & 0.003220 & 0.001698 & 0.025752 & 0.132927 & -0.04266 \\
\hline JPY/PLN & 0.001041 & -0.003480 & 0.039907 & 0.145579 & -0.10261 \\
\hline BTC/PLN & 0.184172 & 0.053388 & 0.588684 & 4.509969 & -0.39755 \\
\hline
\end{tabular}

Source: authors' own calculations.

The mean and median values in Table 1 show that in the analysed sample the monthly rate of return of Bitcoin investments was multiple times higher compared with the returns of other currencies. The average monthly rate of return of the BTC/PLN exchange rate $(0.184172)$ is much higher than the second highest average rate of return for the CHF exchange rate (0.00322), but the risk of investing in Bitcoin measured by the standard deviation of the rate of return is much higher too. At about the 59\% level, it is also significantly higher compared with the risk for JPY, which is ranked as the second riskiest currency. Because the finance theory implies that the risk of investing in a currency can be reduced by opening positions in other currencies 
correlated with the one being analysed, the correlations between the rates of return of Bitcoin and other currencies were determined. The results of this analysis are presented in Table 2.

Table 2 shows a pattern of correlations that are close to zero between the movements in the Bitcoin exchange rate and the exchange rates of other currencies (which are much more strongly related to each other and with only one exception typically exceed the 0.50 level). This result means in practice that hedging a Bitcoin investment by opening the opposite position in some other currency is hardly feasible. At the same time, however, some other existing studies show that a low correlation between the returns of Bitcoin and the returns of other currencies can make Bitcoin investments a valuable supplement in a broader investment process (Carrick, 2016).

Table 2. Correlations between the monthly returns of Bitcoin exchange rates and the monthly returns of five selected PLN currency exchange rates in the period from July 2010 to September 2020

\begin{tabular}{|l|c|c|c|c|c|c|}
\hline & USD/PLN & EUR/PLN & GBP/PLN & CHF/PLN & JPY/PLN & BTC/PLN \\
\hline USD/PLN & 1 & 0.766792 & 0.741642 & 0.65872913 & 0.79077936 & -0.07977 \\
\hline EUR/PLN & & 1 & 0.673414 & 0.52905185 & 0.63460048 & -0.10450 \\
\hline GBP/PLN & & & 1 & 0.47600768 & 0.52531635 & -0.03324 \\
\hline CHF/PLN & & & & 1 & 0.66511965 & -0.06377 \\
\hline JPY/PLN & & & & & 1 & -0.09661 \\
\hline BTC/PLN & & & & & & 1 \\
\hline
\end{tabular}

Source: authors' own calculations.

Another conclusion from Table 2 is that because the behavior of the Bitcoin exchange rate is so much different from the behavior of other foreign exchange rates, the latter are of little use as predictors of Bitcoin's price movements. At the theoretical level, it is unclear, however, why the Bitcoin exchange rate fluctuates so much and whether its volatility can be explained by the macroeconomic factors related to the monetary policy.

In order to address this issue, the second step of our analysis has been focused on the Bitcoin exchange rate's responses to the NBP's monetary policy announcements using the dummy variables introduced in the mean equation of the $\operatorname{GARCH}(1,1)$ model expressed by equation (1). 
The estimation of model (1) parameters was performed in the sample from January 2014 to September 2020 because of the very high dynamics of the BTC/PLN exchange rate in the period before January 2014 (when due to initially a very low level of the nominal price of Bitcoin, the daily returns of BTC/PLN were on some days as high as even $50 \%$ or $60 \%$ ). This issue resulted in the persistent autocorrelation of the error term that could not be eliminated in any way from the model if the sample covered the entire period from the year 2010.

The summary of the types and numbers of NBP monetary policy announcements is shown in Table 3, while the estimation results are presented in Table 4.

Table 3. Summary of the types and numbers of NBP's monetary policy announcements used in model (1) estimation period from January 2014 to September 2020

\begin{tabular}{|l|c|}
\hline \multicolumn{1}{|c|}{ Announcement type } & Number of announcements \\
\hline Interest rate (change) & 5 \\
\hline M3 money supply & 81 \\
\hline Reserves & 81 \\
\hline Monthly current account & 81 \\
\hline Minutes & 73 \\
\hline
\end{tabular}

Source: NBP data compiled by the authors.

The interest rate announcements in our database are defined as the actual changes of the interest rate in Poland (rather than as all announcements regarding the interest rate even when it remained unchanged).

Statistically significant results were obtained for only three out of twenty cases presented in Table 4. The response of the Bitcoin exchange rate to the NBP's announcements was not significant on any of the days when they were revealed. Statistically significant estimates (and only at 5\% and 10\% levels) were obtained for the announcements about the money supply, current account data publication and for the release dates of the minutes of the NBP monetary council meetings. For the M3 money supply, a statistically significant result was obtained one day before it was made, while in the case of current account and minutes it was detected either two days after or two days before these announcements, respectively. However, a change taking place one day or two days before / after the NBP's announcements can hardly be interpreted as caused by the NBP communication, because on other days (in particular: on the announcements days $t$ ) the reaction was not statistically significant. 
Table 4. Responses of the BTC/PLN exchange rate to the NBP monetary policy announcements in the period from January 2014 to September 2020 based on the estimates from model (1)

\begin{tabular}{|c|c|c|c|c|}
\hline Interest rate (change) & M3 money supply & Reserves & $\begin{array}{c}\text { Monthly } \\
\text { current account }\end{array}$ & Minutes \\
\hline \multicolumn{5}{|c|}{ Day $t-2$} \\
\hline $\begin{array}{c}0.011936 \\
(0.622101) \\
\end{array}$ & $\begin{array}{c}0.001119 \\
(0.236415) \\
\end{array}$ & $\begin{array}{c}-0.006094 \\
(-1.167548) \\
\end{array}$ & $\begin{array}{c}0.003891 \\
(0.914182) \\
\end{array}$ & $\begin{array}{c}0.008480 * * \\
(1.969318) \\
\end{array}$ \\
\hline \multicolumn{5}{|c|}{ Day $t-1$} \\
\hline $\begin{array}{c}0.007304 \\
(0.084775) \\
\end{array}$ & $\begin{array}{c}-0.009485 * * * \\
(-2.664159) \\
\end{array}$ & $\begin{array}{c}-0.002559 \\
(-0.659360) \\
\end{array}$ & $\begin{array}{c}-0.002421 \\
(-0.609879) \\
\end{array}$ & $\begin{array}{c}-0.003051 \\
(-0.555550) \\
\end{array}$ \\
\hline \multicolumn{5}{|c|}{ Day $t$} \\
\hline $\begin{array}{c}0.030721 \\
(1.463890)\end{array}$ & $\begin{array}{c}-0.005078 \\
(-0.929121)\end{array}$ & $\begin{array}{c}-0.000873 \\
(-0.181036)\end{array}$ & $\begin{array}{c}0.002642 \\
(0.560443)\end{array}$ & $\begin{array}{c}-0.005084 \\
(-1.106646)\end{array}$ \\
\hline \multicolumn{5}{|c|}{ Day $t+1$} \\
\hline $\begin{array}{c}0.003539 \\
(0.126801)\end{array}$ & $\begin{array}{c}0.001765 \\
(0.393650)\end{array}$ & $0.001457(0.293748)$ & $\begin{array}{c}0.001407 \\
(0.317590)\end{array}$ & $\begin{array}{c}-0.007911 \\
(-1.528323)\end{array}$ \\
\hline \multicolumn{5}{|c|}{ Day $t+2$} \\
\hline $\begin{array}{c}0.000896 \\
(0.056982) \\
\end{array}$ & $\begin{array}{c}0.004817 \\
(0.960582) \\
\end{array}$ & $\begin{array}{c}-0.006312 \\
(-1.578610)\end{array}$ & $\begin{array}{c}-0.016611 * * * \\
(-3.746921)\end{array}$ & $\begin{array}{c}0.000717 \\
(0.148484)\end{array}$ \\
\hline
\end{tabular}

Notes: $t$-statistics are provided in brackets. Statistical significance is denoted as follows: $* * *-$ significant at $p=0.01$ and $* *$ - significant at $p=0.05$.

Source: authors' own estimations.

Therefore, further research is needed to explore and determine whether it is the fundamental data (e.g. information about the state of the economy etc.) that induces statistically significant responses in the Bitcoin exchange rate or whether there exist other types of factors which may better explain Bitcoin's price movements.

Nevertheless, because in this study we have not found even a single case of a statistically significant reaction of the Bitcoin price in Poland on the same day when the NBP was revealing the new data about its monetary policy, we can conclude that there is no evidence that such announcements matter for the determination of the BTC/PLN exchange rate.

\section{Conclusions}

The discussion presented in this paper about Bitcoin and the results of our empirical analyses lead to a few conclusions.

First, Bitcoin does not adequately meet the criteria that money is expected to fulfill. This fact counters the belief of many of its advocates that its characteristics are superior to conventional money. 
Second, the Bitcoin exchange rate is very weakly related to the exchange rates of traditional currencies that are, in turn, strongly correlated with each other. In the period under consideration in our analysis, the returns from investment in Bitcoin were much higher compared with investments in other currencies, but the risk of earning them (measured by the standard deviation of returns) was also substantial.

Third, because the Bitcoin exchange rate was not found to respond statistically significantly to the NBP's monetary policy announcements, the hypothesis that its price varies in response to the release of new macroeconomic data was rejected.

The research results presented in this paper confirmed that in the period of our analysis the Bitcoin was a highly profitable investment, but it was also a very risky financial instrument. Our study has also revealed problems with identification of the causes of fluctuations in the Bitcoin exchange rate. With regard to Poland, we found that in our data sample they were not related to the monetary policy announcements made by the NBP central bank.

\section{References}

Athey, S., Parashkevov, I., Sarukkai, V., Jing Xia, J. (2016). Bitcoin Pricing, Adoption, and Usage: Theory and Evidence. Working Paper No. 17-033 B, Institute for Economic Policy Research, Stanford University.

Bal, A. (2015). How to Tax Bitcoin. In: D.L.K. Chuen (ed.), Handbook of digital currency: Bitcoin, innovation, financial instruments, and big data (pp. 267-282). Academic Press.

Bartos. J. (2015). Does Bitcoin Follow the Hypothesis of Efficient Market? International Journal of Economic Sciences, 4, 10-23. DOI: 10.20472/ES.2015.4.2.002

Bitcoin Block Reward Halving Countdown (2020). Retrieved from: https://www.bitcoinblockhalf.com.

Brzeszczyński, J., Gajdka, J., Kutan, A. (2017). Central Bank Communication and the Impact of Public Announcements of New Monetary Policy Data on the Reaction of Foreign Exchange and Stock Markets: Evidence from Poland. Argumenta Oeconomica, 39, 21-60. DOI: 10.15611/aoe.2017.2.02.

Brzeszczyński, J., Gajdka, J., Kutan, A. (2019). Evolution of the Impact of the Interest Rates Changes Announced by the National Bank of Poland (NBP) on the Financial Markets in the High, Medium and Low Level of Interest Rates Environments in Poland. Materiaty i Studia, 303, 1-101, Narodowy Bank Polski (NBP), Warszawa. 
Brzeszczyński, J., Kutan, A.M. (2015). Public Information Arrival and Investor Reaction During a Period of Institutional Change: An Episode of Early Years of a Newly Independent Central Bank. Journal of Comparative Economics, 43, 727-753. DOI: 10.1111/1468-0297.00558.

Carrick, J. (2016). Bitcoin as a Complement to Emerging Market Currencies. Emerging Markets Finance and Trade, 52, 2321-2334. DOI: 10.1080/1540496X.2016.1193002.

Choo, K.K.R. (2015). Cryptocurrency and Virtual Currency: Corruption and Money Laundering/Terrorism Financing Risks? In: D.L.K. Chuen (ed.), Handbook of digital currency: Bitcoin, innovation, financial instruments, and big data (pp. 283-307). Academic Press. DOI: 10.1016/B978-0-12-802117-0.00015-1.

Fessenden, H. (2018). When Banking Was 'Free'. Econ Focus, Federal Reserve Bank of Richmond, Issue 1Q, pp. 28-30.

Huang, J., Huang, W., Ni, J. (2019). Predicting Bitcoin Returns Using High-dimensional Technical Indicators, Journal of Finance and Data Science, 5, 140-155. DOI: 10.1016/j. jfds.2018.10.001.

Jak inwestować w Bitcoin (2020). Retrieved from: https://www.xtb.com/pl/inwestowanie-wbitcoin-kb.

Ji, S., Kim, J., Im, H. (2020). A Comparative Study of Bitcoin Price Prediction Using Deep Learning. Mathematics, 7, 1-20. DOI: 10.3390/math7100898.

Kacwin, M., Piech, K. (2017). Stan Rynku Kryptowalut w Polsce oraz Możliwe Przychody Podatkowe Budżetu Państwa, Program „Od Papierowej do Cyfrowej Polski” Strumień Blockchain/DLT i Waluty Cyfrowe. Retrieved from: https://www.gov.pl/documents/31305/436699/Stan+rynku+kryptowalut+w+Polsce.pdf/ceb489cf-aaf5-fdef-fb04$62724 \mathrm{e} 1 \mathrm{~b} 62 \mathrm{~b} 9$.

Kossov, N., Dykes, V. (2018). Blockchain, Bitcoin and Corruption. A Review of the Linkages, Transparency International, 1-18.

Levin, R.B., O’Brien, A.A., Zuberi, M.M. (2015). Real Regulation of Virtual Currencies. In: D.L.K. Chuen (ed.), Handbook of digital currency: Bitcoin, innovation, financial instruments, and big data (pp. 227-360). Academic Press.

Lim, J.W. (2015). A Facilitative Model for Cryptocurrency in Singapore. In: D.L.K. Chuen (ed.), Handbook of digital currency: Bitcoin, innovation, financial instruments, and big data (pp. 361-381). Academic Press.

Lo, S., Wang, J.Ch. (2014). Bitcoin as a Money? Current Policy Perspectives. Federal Reserve Bank of Boston, No. 14-4, pp. 1-28.

Marian, O.Y. (2015). A Conceptual Framework for the Regulation of Cryptocurrencies, Chicago Law Review Dialogue, 53, 1-17.

Marian, O.Y. (2013). Are Cryptocurrencies 'Super' Tax Havens? Michigan Law Review First Impressions, 112, 1-12. 
Mukherji, S. (2020). Empirical Evidence on Bitcoin Returns and Portfolio Value. International Journal of Business and Finance Research, 13, 71-81.

Nakamoto, S. (2008). Bitcoin: A Peer to Peer Electronic Cash System. Retrieved from: https:// bitcoin.org/bitcoin.pdf.

Nian, L.P., Chuen, D.L.K. (2015a). A Light Touch of Regulation for Virtual Currencies. In: D.L.K. Chuen (ed.), Handbook of digital currency: Bitcoin, innovation, financial instruments, and big data (pp. 309-326). Academic Press.

Nian, L.P., Chuen, D.L K. (2015b). Intruduction to Bitcoin. In: D.L.K. Chuen (ed.), Handbook of digital currency: Bitcoin, innovation, financial instruments, and big data (pp. 5-30). Academic Press.

Plassaras, N.A. (2013). Regulating Digital Currencies Binging Bitcoin Within the Reach of the IMF. Journal of International Law, 14, 1-35.

Roberts, J. (2017). Only 802 People Told the IRS About Bitcoin. Retrieved from: http://fortune. com/2017/03/19/irs-bitcoinlawsuit.

Rosenfeld, M. (2011). Analysis of Bitcoin Pooled Mining Reward Systems. Retrieved from: https://bitcoil.co.il/pool_analysis.pdf.

Saito, T. (2015). A Microeconomic Analysis of Bitcoin and Illegal Activities. In: D.L.K. Chuen (ed.), Handbook of digital currency: Bitcoin, innovation, financial instruments, and big data (pp. 231-247). Academic Press.

Saleem, S.Z. (2018). The 2008 Global Meltdown and the Birth of Bitcoin. Retrieved from: https://www.livemint.com/Money/YTYMYUD7dytGK5PGSpdRTN/The-2008-globalmeltdown-and-the-birth-of-Bitcoin.html.

Sapovadia, V. (2015). Legal Issues in Cryptocurrency. In: D.L.K. Chuen (ed.), Handbook of digital currency: Bitcoin, innovation, financial instruments, and big data (pp. 253-266). Academic Press.

Wang, J.C.Y. (2014). A Simple Macroeconomic Model of Bitcoin. SSRN Working Paper. Retrieved from: https://ssrn.com/abstract=2394024.

Wesner, N. (2015). Extracting Market-Implied Bitcoin's Risk-Free Interest Rate. In: D.L.K. Chuen (ed.), Handbook of digital currency: Bitcoin, innovation, financial instruments, and big data (pp. 223-230). Academic Press.

Vujičić, D., Jagodić, D., Ranđić, S. (2018). Blockchain Technology, Bitcoin and Ethereum: A Brief Overview (pp. 1-6). 17th International Symposium INFOTEH-JAHORINA (INFOTEH), East Sarajevo 2018. Retrieved from: https://www.researchgate.net/publication/324791073_Blockchain_technology_bitcoin_and_Ethereum_A_brief_overview. DOI: 10.1109/INFOTEH.2018.8345547.

Yermack, D. (2015). Is Bitcoin a Real Currency. In: D.L.K. Chuen (ed.), Handbook of digital currency: Bitcoin, innovation, financial instruments, and big data (pp. 31-43). Academic Press. 